\title{
Catalytic combustion of methane over cobalt doped lanthanum stannate pyrochlore oxide
}

\author{
Jie Cheng ${ }^{\text {a }}$, Hailin Wang ${ }^{\mathrm{a}}$, Zhengping Hao ${ }^{\mathrm{a}, *}$, Shaobin Wang ${ }^{\mathrm{b}}$ \\ ${ }^{a}$ Research Center for Eco-Environmental Sciences, Chinese Academy of Sciences, Beijing 100085, PR China \\ ${ }^{\mathrm{b}}$ Department of Chemical Engineering, Curtin University of Technology, GPO Box U1987, Perth, WA 6845, Australia
}

Received 12 June 2007; received in revised form 9 August 2007; accepted 13 August 2007

Available online 17 August 2007

\begin{abstract}
A series of $\mathrm{La}_{2} \mathrm{Co}_{x} \mathrm{Sn}_{2-x} \mathrm{O}_{7-\delta}$ oxides with pyrochlore structure have been synthesized by the co-precipitation method as high-temperature catalysts for methane combustion. The dopant strongly influences the thermal stability and redox properties of these pyrochlores. IR measurements show that the $\mathrm{Sn}-\mathrm{O}$ bond strength was weakened with increasing amount of Co doped in the $\mathrm{La}_{2} \mathrm{Sn}_{2} \mathrm{O}_{7}$, thus promoting the formation of oxygen vacancy. The reduction rates and the amount of oxygen vacancy would significantly affect catalytic activities of $\mathrm{La}_{2} \mathrm{Co}_{x} \mathrm{Sn}_{2-x} \mathrm{O}_{7-\delta}$ in $\mathrm{CH}_{4}$ oxidation. Among the doped pyrochlores, $\mathrm{La}_{2} \mathrm{Co}_{0.3} \mathrm{Sn}_{1.7} \mathrm{O}_{7-\delta}$ and $\mathrm{La}_{2} \mathrm{Co}_{0.5} \mathrm{Sn}_{1.5} \mathrm{O}_{7-\delta}$ possessed optimum activities for methane combustion at low and high temperature, respectively.
\end{abstract}

(C) 2007 Elsevier B.V. All rights reserved.

Keywords: Methane; Catalytic combustion; Lanthanum stannate pyrochlore; Metal ion doping

\section{Introduction}

Worldwide interest towards the developments of catalytic combustion of methane in various academic and technological aspects is actively continuing, due to its potential application for production of energy with ultra low emissions of $\mathrm{NO}_{x}, \mathrm{CO}$, and unburned hydrocarbons $[1,2]$. However, one of the main problems in the development of the catalytic combustion process is the finding of suitable catalysts with high thermal stability and high activity [3]. Noble metal-based catalysts are well-known to be active for methane oxidation at low temperatures, however, they are too expensive and also not stable at high temperatures [4]. Although metal-substituted hexaaluminates are deemed to be the most promising materials for high temperature combustion, they are difficult to be synthesized and their activities at low temperatures $\left(<600{ }^{\circ} \mathrm{C}\right)$ are not ideal $[5,6]$.

\footnotetext{
${ }^{*}$ Corresponding author. Tel.: +86 10 62849194; fax: +86 1062923564. E-mail address: zpinghao@rcees.ac.cn (Z. Hao).
}

Pyrochlores $\left(\mathrm{A}_{2} \mathrm{~B}_{2} \mathrm{O}_{7}\right)$ form an isostructural family of general formula $\mathrm{A}_{2} \mathrm{~B}_{2} \mathrm{O}_{7}$ have a structure composed of two different types of cation coordination polyhedra, in which the A-site positions typically occupied by larger cations are eight-fold coordination while the B-site positions favored by smaller sized cations are six-fold coordination [7]. Their structure formula is often written as $\mathrm{B}_{2} \mathrm{O}_{6} \cdot \mathrm{A}_{2} \mathrm{O}^{\prime}$, which emphasizes that the arrangement consists of a threedimensional network of octahedral $\left(\mathrm{B}_{2} \mathrm{O}_{6}\right)$ linked with an $\mathrm{A}_{2} \mathrm{O}^{\prime}$ tetrahedral in the interstices [8].

Pyrochlores have attracted considerable interest due to their excellent thermal stability and catalytic activities at high temperatures. They have been applied in various reactions such as $\mathrm{CO}-\mathrm{NO}$ reaction [9], CO oxidation [10] and oxidative coupling of methane [11]. In addition, the structure also tolerates a wide variety of substitutions of metals into the lattice and hence the properties of the material can be tailored [12].

Pyrochlore-type oxides containing transition metals are attracting great attention as catalysts for complete oxidation of methane because of its considerably large SSA 
and catalytic activity at high temperatures [13-15]. Recently, Moon et al. $[13,14]$ found that manganese-doped samarium stannate pyrochlore $\left(\mathrm{Sm}_{2} \mathrm{Sn}_{1.8} \mathrm{Mn}_{0.2} \mathrm{O}_{7}\right)$ possessed good combustion activity of methane. Sohn and Woo [15] reported that $\mathrm{Sm}_{2} \mathrm{Zr}_{2} \mathrm{O}_{7}$ with pyrochlore structure is more active than $\mathrm{Sr}_{0.8} \mathrm{La}_{0.2} \mathrm{MnAl}_{11} \mathrm{O}_{19}$, which is known to show the highest activity in $\mathrm{CH}_{4}$ combustion.

However, to our knowledge, there is no research exploring other transition metal doped lanthanide stannate pyrochlore for methane combustion. It is generally known that cobalt has turned out to be one of the best combustion catalysts according to the so-called volcano plots [16]. In the present work, we have investigated the influence of Co-dopant on the properties of lanthanum stannate pyrochlore for methane catalytic combustion, targeting at catalytic materials with high performance. We have prepared a series of $\mathrm{La}_{2} \mathrm{Co}_{x} \mathrm{Sn}_{2-x} \mathrm{O}_{7-\delta}(x=0,0.1,0.3,0.5$, $0.7,1)$ catalysts using aqueous precipitation method and characterized their properties with BET, XRD, DTGDSC, TPD/TPR, IR techniques. The relationship between catalytic activity with material composition, phase structure, and micro-morphology was obtained.

\section{Experimental}

\subsection{Catalyst preparation}

Various $\mathrm{La}_{2} \mathrm{Co}_{x} \mathrm{Sn}_{2-x} \mathrm{O}_{7-\delta}$ catalysts were prepared with a constant-pH coprecipitation method where $x$ was set at $0.0,0.1,0.3,0.5,0.7$, and 1.0. Typically, a mixed salt solution $(100 \mathrm{ml})$ and a $100 \mathrm{ml}$ basic solution $(\mathrm{NaOH})$ were simultaneously added dropwise into $100 \mathrm{ml}$ of doubly distilled water during $1 \mathrm{~h}$ at constant $\mathrm{pH}(9.5 \pm 0.5)$ under vigorous stirring. The salt solution with a total metal concentration of $1.0 \mathrm{M}$ contains suitable amounts of $\mathrm{La}\left(\mathrm{NO}_{3}\right)_{3} \cdot 9 \mathrm{H}_{2} \mathrm{O}(>99 \%$, Beijing Chemical Industry Company), $\mathrm{Co}\left(\mathrm{NO}_{3}\right)_{2} \cdot 6 \mathrm{H}_{2} \mathrm{O}(>99 \%$, Beijing Chemical Industry Company), and $\mathrm{SnCl}_{4}(>99 \%$, Beijing Chemical Industry Company). Precipitates were aged in suspension for $4 \mathrm{~h}$ under stirring in static air and then filtered and thoroughly washed with doubly distilled water. The cake was dried at $70{ }^{\circ} \mathrm{C}$ for $12 \mathrm{~h}$ and further dried at $120^{\circ} \mathrm{C}$ overnight. Finally catalysts were calcined at $900^{\circ} \mathrm{C}$ for $5 \mathrm{~h}$.

\subsection{Catalyst characterization}

The XRD patterns were recorded using a Rigaku powder diffractometer $(\mathrm{D} / \mathrm{max}-\mathrm{RB})$ using $\mathrm{Cu} \mathrm{K} \alpha$ radiation $(\lambda=0.15418 \mathrm{~nm})$ in the $2 \theta$ range of $10-70^{\circ}$ at scanning rate of $4^{\circ}$ per min. The tube voltage and current were set at $40 \mathrm{KV}$ and $30 \mathrm{~mA}$, respectively.

The BET surface areas of the solid catalysts were measured by $\mathrm{N}_{2}$ adsorption at liquid nitrogen temperature $\left(-196^{\circ} \mathrm{C}\right)$ in a Quantachrome NOVA 1200 Sorptomatic apparatus. The specific surface area was calculated with the BET equation.
The thermal decomposition and stability of $\mathrm{La}_{2} \mathrm{Co}_{x} \mathrm{Sn}_{2-x} \mathrm{O}_{7-\delta}$ samples was studied by thermogravimetry and differential scanning calorimetry (TG and DSC, Seteram, Labsys ${ }^{\mathrm{TM}}$ ). In a typical run, $20-30 \mathrm{mg}$ of $\mathrm{La}_{2} \mathrm{Co}_{x} \mathrm{Sn}_{2-x} \mathrm{O}_{7}$ sample was heated in an $\mathrm{Al}_{2} \mathrm{O}_{3}$ crucible at a constant heating rate of $10^{\circ} \mathrm{C} / \mathrm{min}$ from 15 to $1000{ }^{\circ} \mathrm{C}$, with air flow at a rate of $30 \mathrm{~mL} / \mathrm{min}$.

Hydrogen temperature-programmed reduction $\left(\mathrm{H}_{2}-\right.$ TPR) of all the $\mathrm{La}_{2} \mathrm{Co}_{x} \mathrm{Sn}_{2-x} \mathrm{O}_{7-\delta}$ catalysts was performed on a conventional TPR apparatus equipped with a thermal conductivity detector (TCD). The catalyst samples $(50 \mathrm{mg})$ were placed in a quartz reactor land sandwiched between two quartz wool plugs. Prior to each TPR run, the catalyst was heated up to $500{ }^{\circ} \mathrm{C}$ under $\mathrm{O}_{2}$ flow $(40 \mathrm{~mL} / \mathrm{min})$. After 30 min pretreatment in the $\mathrm{O}_{2}$ flow at $500{ }^{\circ} \mathrm{C}$, the reactor bed temperature was then lowered down to room temperature by keeping the same flow rate of oxygen. Then $\mathrm{N}_{2}$ was fed to the reactor at $30 \mathrm{~mL} / \mathrm{min}$ for $1 \mathrm{~h}$ at room temperature to purge any residual oxygen. The catalyst was then heated to $750{ }^{\circ} \mathrm{C}$ at a constant heating rate of $10^{\circ} \mathrm{C} / \mathrm{min}$ using $\mathrm{H}_{2}$ under a flow rate of $30 \mathrm{~mL} / \mathrm{min} . \mathrm{H}_{2}$ consumption was monitored by the TCD detector.

The infrared (IR) absorption spectra were recorded on a Bruker Tensor 27 spectrometer with 32 scans at an effective resolution of $4 \mathrm{~cm}^{-1}$ (wave number from 600 to $4000 \mathrm{~cm}^{-1}$ ). The powders were mixed with $\mathrm{KBr}$ at the mass ratio of 1:100, and then pressed into thin and transparent slices for analysis.

\subsection{Catalyst evaluation}

The catalytic activity evaluations for methane combustion on various $\mathrm{La}_{2} \mathrm{Co}_{x} \mathrm{Sn}_{2-x} \mathrm{O}_{7-\delta}$ catalysts were carried out in a tubular plug flow reactor at atmospheric pressure. A mixture of $\mathrm{CH}_{4}$ :air in a volume ratio of 1:99 at a total flow rate of $400 \mathrm{~mL} / \mathrm{min}$ was passed through the catalyst bed $(0.5 \mathrm{~g}$ catalyst diluted with similar volume silica). The GHSV was kept approximately at $50,000 \mathrm{~mL} / \mathrm{g} \mathrm{h}$. The reaction system was heated externally via a tubular furnace. The reactants and products were analyzed online by a GC equipped with FID. $\mathrm{CO}$ and $\mathrm{CO}_{2}$ were catalytically converted to $\mathrm{CH}_{4}$ by a Ni catalyst prior to the FID measurements. The methane conversion rate was calculated based on the integrated GC peak areas. The catalysts activity was characterized by $T_{10}, T_{50}, T_{90}$ representing the temperature at methane conversion of $10 \%, 50 \%$, and $90 \%$, respectively.

\section{Results and discussion}

\subsection{Physicochemical characterization}

\subsection{1. $\mathrm{X}$-ray diffraction analysis of $\mathrm{La}_{2} \mathrm{Co}_{x} \mathrm{Sn}_{2-x} \mathrm{O}_{7-\delta}$}

In order to determine the phase composition of various $\mathrm{La}_{2} \mathrm{Co}_{x} \mathrm{Sn}_{2-x} \mathrm{O}_{7-\delta}$ catalysts, XRD experiments were performed. Fig. 1. shows the XRD patterns of $\mathrm{La}_{2} \mathrm{Sn}_{2} \mathrm{O}_{7}$ doped with the different amounts of Co ions. It can be seen 


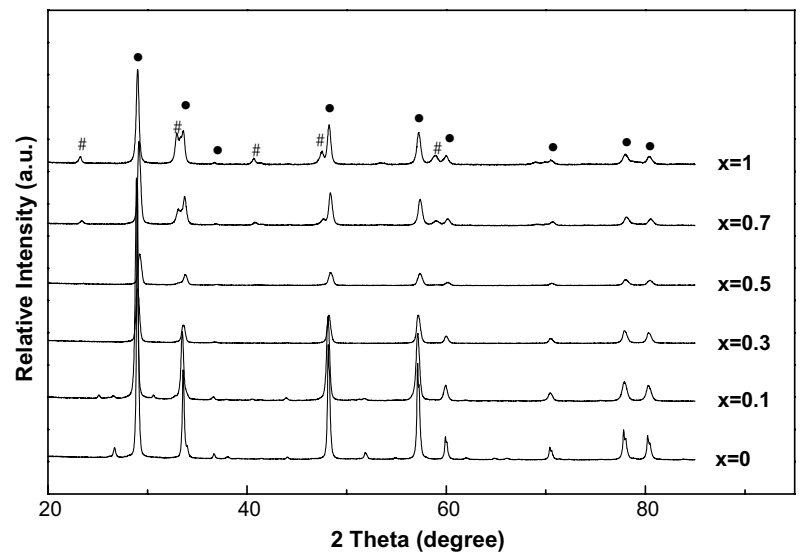

Fig. 1. XRD patterns of $\mathrm{La}_{2} \mathrm{Co}_{x} \mathrm{Sn}_{2-x} \mathrm{O}_{7-\delta}$ catalysts where $\mathrm{La}_{2} \mathrm{Sn}_{2} \mathrm{O}_{7}$ phase was marked as "." and $\mathrm{LaCoO}_{3}$ phase as "\#”.

that all these samples show the typical diffraction peaks at $2 \theta \approx 29,48$ and 57, attributed to the (222), (440), and (622) crystal planes of $\mathrm{La}_{2} \mathrm{Sn}_{2} \mathrm{O}_{7}$ (JCPDS 13-0082) with cubic lanthanum stannate pyrochlore structure. These characteristic diffractions indicate that the cobalt metal cations are well distributed in the pyrochlore structure and a small quantity of the doped ions in the pyrochlores does not change the crystal purity since there is no peak related with other compounds. However, a weak signal for rhombohedral $\mathrm{LaCoO}_{3}$ (JCPDS 09-0358) was detected in the crystalline phase of the $\mathrm{La}_{2} \mathrm{Co}_{x} \mathrm{Sn}_{2-x} \mathrm{O}_{7-\delta}$ catalyst at higher $\mathrm{Co}$ composition with $x \geqslant 0.7$. These results reveal that the doping limit of Co into $\mathrm{La}_{2} \mathrm{Sn}_{2} \mathrm{O}_{7}$ is $x<0.7$.

\subsubsection{DTG-DSC profiles of $\mathrm{La}_{2} \mathrm{Co}_{x} \mathrm{Sn}_{2-x} \mathrm{O}_{7-\delta}$ precursors}

The DTG-DSC profiles of $\mathrm{La}_{2} \mathrm{Co}_{x} \mathrm{Sn}_{2-x} \mathrm{O}_{7-\delta}$ precursors after drying at $110^{\circ} \mathrm{C}$ are shown in Figs. 2 and 3. The DSC graph shows an endothermic peak in the temperature range of $100-200{ }^{\circ} \mathrm{C}$ accompanied in the TG graph by a weight loss, which is attributed to the removal of adsorbed water. In the temperature range of $200-600^{\circ} \mathrm{C}$, a great and progressive weight loss is observed, which

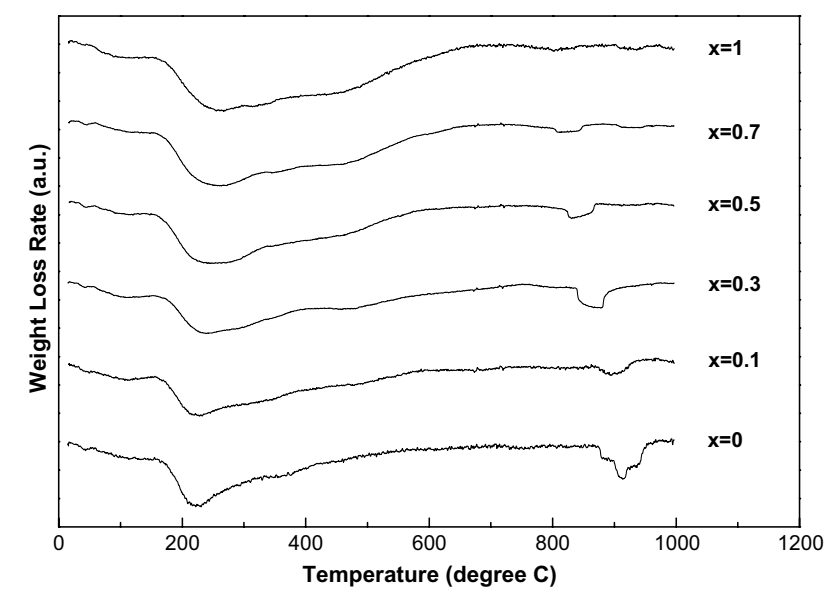

Fig. 2. DTG profiles of $\mathrm{La}_{2} \mathrm{Co}_{x} \mathrm{Sn}_{2-x} \mathrm{O}_{7-\delta}$ precursors.

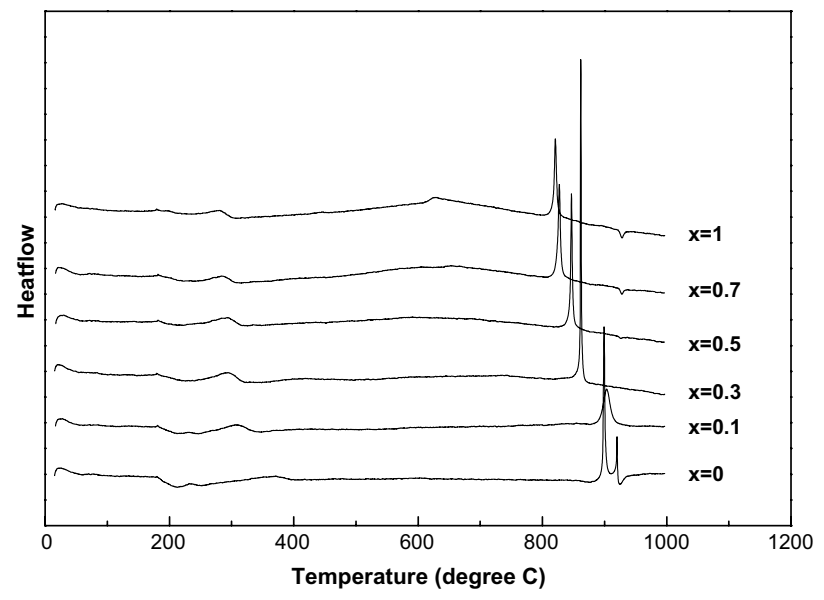

Fig. 3. DSC profiles of $\mathrm{La}_{2} \mathrm{Co}_{x} \mathrm{Sn}_{2-x} \mathrm{O}_{7-\delta}$ precursors.

can be attributed to the decomposition of hydroxides. When the temperature is raised to $800{ }^{\circ} \mathrm{C}$, an upwardssteep curve representing the characteristic of an exothermic peak can be obviously observed in the DSC spectra. It was believed that the exothermic phenomena might be resulted from the crystallization of the pyrochlore cubic phase. From the overall change of the curve, $900{ }^{\circ} \mathrm{C}$ appears to be the optimum temperature to calcine powders. It is clearly noted that, with the increase of cobalt content in $\mathrm{La}_{2} \mathrm{Co}_{x} \mathrm{Sn}_{2-x} \mathrm{O}_{7-\delta}$, the temperature of phase formation of pyrochlore reduces by $50{ }^{\circ} \mathrm{C}$ to $100{ }^{\circ} \mathrm{C}$. The results of DTG-DSC further prove the interactions between $\mathrm{Sn}$ and $\mathrm{Co}$ and the improving effects of cobalt metal dopants on the phase formations of pyrochlores.

\subsubsection{IR spectra of $\mathrm{La}_{2} \mathrm{Co}_{x} \mathrm{Sn}_{2-x} \mathrm{O}_{7-\delta}$ catalysts}

In pyrochlores the metal ions are situated in two different sub-lattices designated tetrahedral (A site) and octahedral (B site) according to the geometrical configuration of the neighboring oxygen. It was reported that pyrochlore oxides exhibited seven IR bands in the range of 750 $50 \mathrm{~cm}^{-1}$ originating from vibration and bending of metaloxygen bonds in the IR spectra of the pyrochlore oxides [7]. The band at about $600 \mathrm{~cm}^{-1}$ is from the $\mathrm{B}-\mathrm{O}$ stretching vibrations in the $\mathrm{BO}_{6}$ octahedron and the band around $400 \mathrm{~cm}^{-1}$ to the $\mathrm{A}-\mathrm{O}^{\prime}$ stretching vibrations. The IR spectra of the catalysts recorded in the range of $400-900 \mathrm{~cm}^{-1}$ are shown in Fig. 4. In this region, only one broad band ascribed to $\mathrm{Sn}-\mathrm{O}$ stretching vibration, was observed for all catalysts and the maximum frequency of the band, $v(\mathrm{Sn}-\mathrm{O})$, gradually shifts to low frequency, indicating that the $\mathrm{Sn}-\mathrm{O}$ bond strength weakens with the increasing amount of Co doped in the lanthanum stannate pyrochlore. The replacement of bigger ion $\left(\mathrm{Sn}^{4+}\right)$ by a smaller ion $\left(\mathrm{Co}^{3+}\right)$ has remarkable influence on the bonding character of $\mathrm{B}-\mathrm{O}$ ions. It was reported that the difference in the $\mathrm{Sn}-\mathrm{O}$ bond strength would affect oxygen vacancy formation [17], and that $\mathrm{Sn}-\mathrm{O}$ bonding energy is always lower than $\mathrm{La}-\mathrm{O}$. Based on these facts, Moon et al. [14] consider 


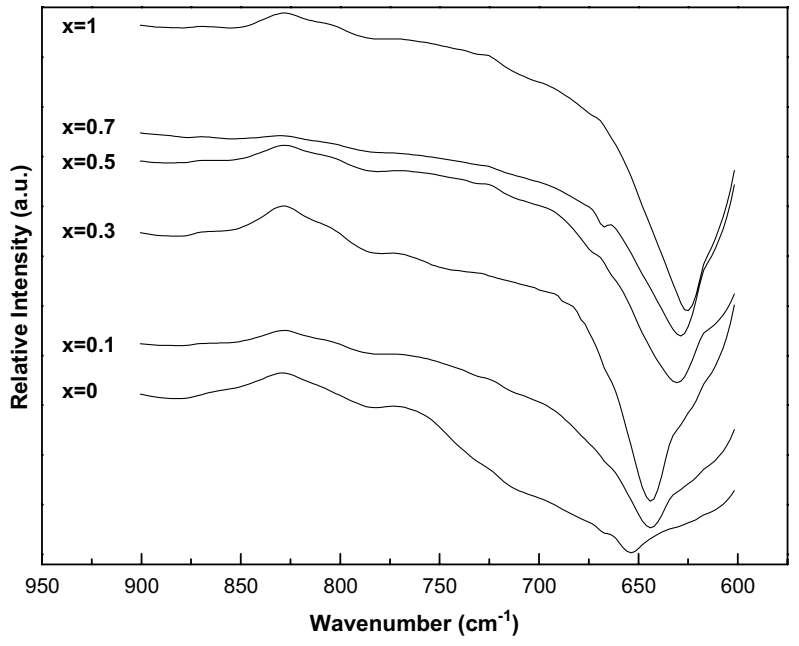

Fig. 4. IR spectra of $\mathrm{La}_{2} \mathrm{Co}_{x} \mathrm{Sn}_{2-x} \mathrm{O}_{7-\delta}$ catalysts.

that the release of lattice oxygen mainly resulted from the $\mathrm{Sn}-\mathrm{O}$ bond breakage.

\subsubsection{TPR profiles of $\mathrm{La}_{2} \mathrm{Co}_{x} \mathrm{Sn}_{2-x} \mathrm{O}_{7-\delta}$ catalysts}

The temperature programmed reduction (TPR) technique was used to investigate the redox properties of $\mathrm{La}_{2} \mathrm{Co}_{x} \mathrm{Sn}_{2-x} \mathrm{O}_{7-\delta}$ catalysts and the TPR profiles are depicted in Fig. 5. There is a wide $\mathrm{H}_{2}$ consumption peak between $550{ }^{\circ} \mathrm{C}$ and $750{ }^{\circ} \mathrm{C}$ occurring on $\mathrm{La}_{2} \mathrm{Sn}_{2} \mathrm{O}_{7}$ TPR profile, which is due to the reduction of $\mathrm{Sn}^{4+}$ to $\mathrm{Sn}^{0}$. For $\mathrm{La}_{2} \mathrm{Co}_{0.1} \mathrm{Sn}_{1.9} \mathrm{O}_{7-\delta}$ catalyst, the $\mathrm{H}_{2}$ reduction peak is shifted towards low temperature at $500-600{ }^{\circ} \mathrm{C}$. This shift is ascribed to the decrease of $\mathrm{Sn}-\mathrm{O}$ bond energy in the pyrochlore by the Co incorporation. A further reduction behavior is also observed on the catalysts of $\mathrm{La}_{2} \mathrm{Co}_{0.3} \mathrm{Sn}_{1.7} \mathrm{O}_{7-\delta}$ and $\mathrm{La}_{2} \mathrm{Co}_{0.5} \mathrm{Sn}_{1.5} \mathrm{O}_{7-\delta}$, which present a large $\mathrm{H}_{2}$ consumption peak around $375^{\circ} \mathrm{C}$, which was attributed to the reduction of $\mathrm{Co}^{3+}$ to $\mathrm{Co}^{2+}$. The complete reduction of $\mathrm{Co}^{2+}$ to $\mathrm{Co}^{0}$ only takes place at higher temperature. With the increase of $x$ values $(x>0.7), \mathrm{H}_{2}$ reduction peak is shifted to high temperature, due to the formation of difficult reducible $\mathrm{LaCoO}_{3}$ revealing by the XRD results.

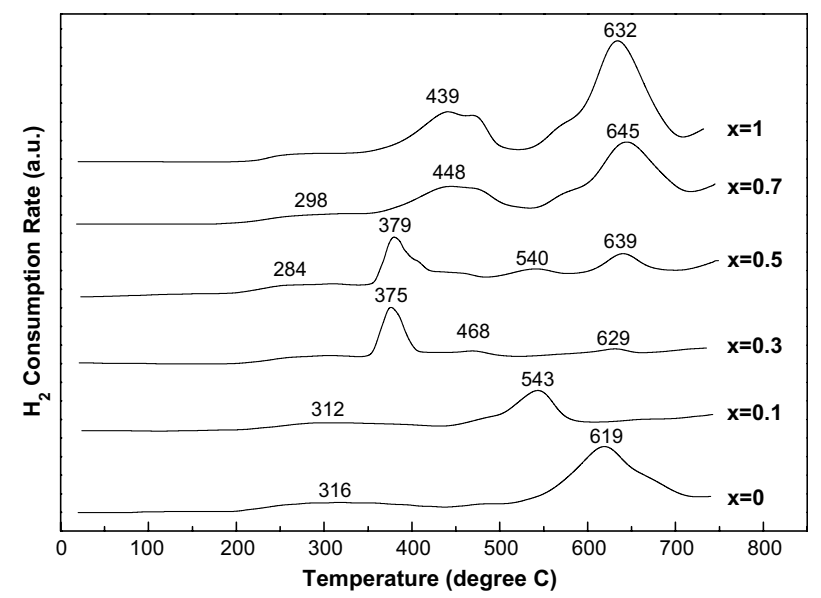

Fig. 5. TPR profiles of $\mathrm{La}_{2} \mathrm{Co}_{x} \mathrm{Sn}_{2-x} \mathrm{O}_{7-\delta}$ catalysts.
3.2. Catalytic activities of $\mathrm{La}_{2} \mathrm{Co}_{x} \mathrm{Sn}_{2-x} \mathrm{O}_{7-\delta}$ catalysts for methane combustion

Fig. 6. shows the catalytic activities of methane oxidation over the Co-doped lanthanum stannate pyrochlores prepared. In this investigation, carbon dioxide is the sole product; carbon monoxide was scarcely detected during oxidation. It is seen that methane conversion increases with increasing temperature and reaches $100 \%$ around 700 $750{ }^{\circ} \mathrm{C}$. Linear Arrhenius plots corresponding to a simple first-order rate model by assuming an integral mode were also obtained from lower conversions up to $50 \%$ and presented in Fig. 7. Catalytic activities in terms of $T_{10}, T_{50}$, $T_{90}$, surface areas and apparent activation energies are listed in Table 1. Activities of all Co-doped lanthanum stannates pyrochlores are apparently superior to that of $\mathrm{La}_{2} \mathrm{Sn}_{2} \mathrm{O}_{7}$, indicating that the Co component plays an important role in methane combustion on pyrochlores. The $\mathrm{La}_{2} \mathrm{Co}_{0.5} \mathrm{Sn}_{1.5} \mathrm{O}_{7-\delta}$ shows the best activity and other catalysts present varying catalytic activity depending on Co content following the order of $x=0.3,0.7,1,0.1$. Table 1. also shows that Co doping reduces the activated energy and $\mathrm{La}_{2} \mathrm{Co}_{0.3} \mathrm{Sn}_{1.7} \mathrm{O}_{7-\delta}$ has the lowest value.

Reactivity of metal oxides is largely dependent on the degree of the coordinative unsaturation of the metal ions. The incorporation of cobalt ions in the pyrochlore structure leads to the formation of oxygen vacancies and makes local structure changed where the coordinative unsaturation of specific $\mathrm{Sn}$ ions increases. Oxygen vacancies are produced with the replacement of $\mathrm{Sn}^{4+}$ by a valence lower than $4+$ to maintain electrostatic charge neutrality. In general, the catalytic activity of the catalysts is attributed to the surface oxygen vacancy formed during the breakage of metaloxygen lattice bond.

In general, specific surface area of a catalyst will affect catalytic activity. The surface areas of all the catalysts are in the range of $10-20 \mathrm{~m}^{2} / \mathrm{g}$. Incorporation of Co into the pyrochlore lattice decreased the surface area to some extent compared with the undoped $\mathrm{La}_{2} \mathrm{Sn}_{2} \mathrm{O}_{7}\left(19 \mathrm{~m}^{2} / \mathrm{g}\right)$. It is

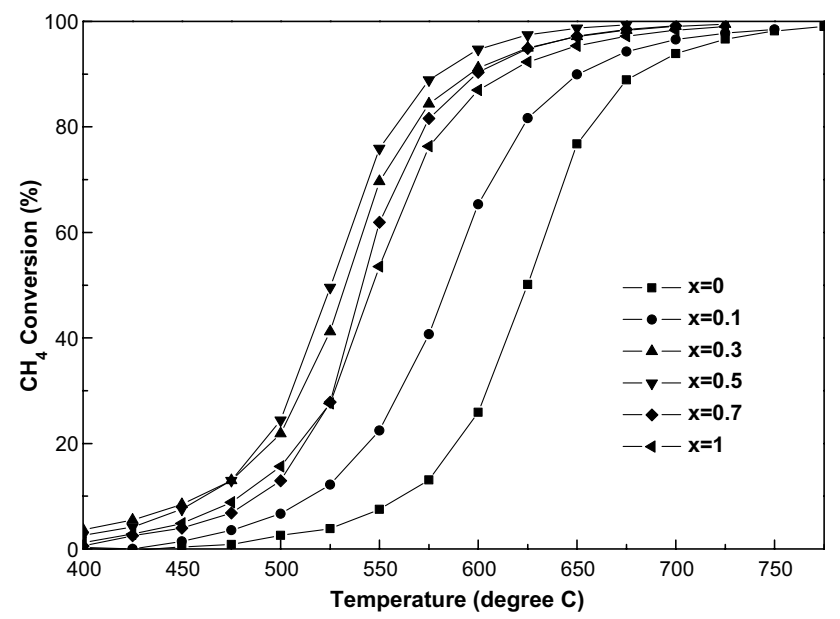

Fig. 6. Temperature dependence of methane catalytic combustion on $\mathrm{La}_{2} \mathrm{Co}_{x} \mathrm{Sn}_{2-x} \mathrm{O}_{7-\delta}$ catalysts. 


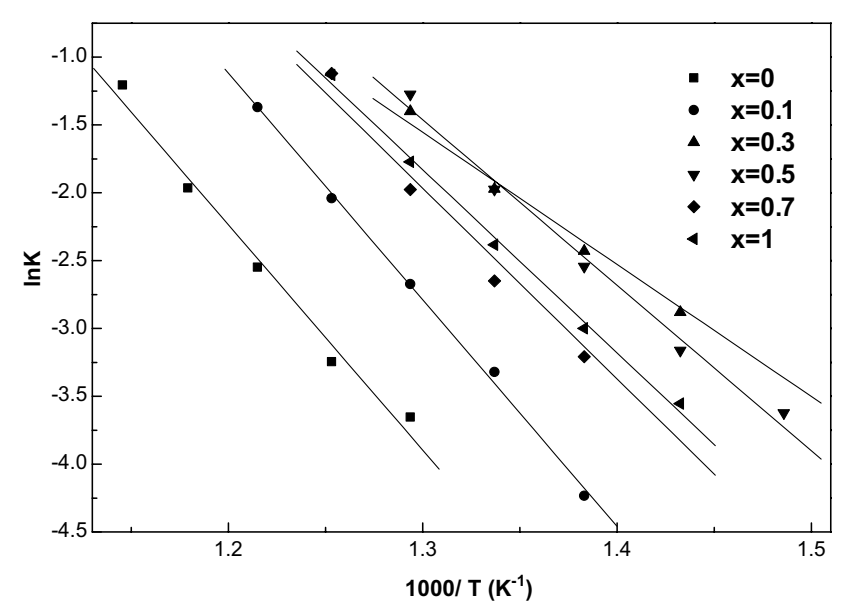

Fig. 7. Arrhenius plots for the $\mathrm{La}_{2} \mathrm{Co}_{x} \mathrm{Sn}_{2-x} \mathrm{O}_{7-\delta}$ catalysts.

Table 1

The BET surface areas and catalytic activity of $\mathrm{La}_{2} \mathrm{Co}_{x} \mathrm{Sn}_{2-x} \mathrm{O}_{7-\delta}$ catalysts

\begin{tabular}{lllllc}
\hline Catalysts & $\begin{array}{l}T_{10} \\
\left({ }^{\circ} \mathrm{C}\right)\end{array}$ & $\begin{array}{l}T_{50} \\
\left({ }^{\circ} \mathrm{C}\right)\end{array}$ & $\begin{array}{l}T_{90} \\
\left({ }^{\circ} \mathrm{C}\right)\end{array}$ & $\begin{array}{l}\text { SSA } \\
\left(\mathrm{m}^{2} / \mathrm{g}\right)\end{array}$ & $\begin{array}{l}E_{\mathrm{a}} \\
(\mathrm{kJ} / \mathrm{mol})\end{array}$ \\
\hline $\mathrm{La}_{2} \mathrm{Sn}_{2} \mathrm{O}_{7}$ & 562 & 624 & 682 & 19.0 & 138.1 \\
$\mathrm{La}_{2} \mathrm{Co}_{0.1} \mathrm{Sn}_{1.9} \mathrm{O}_{7-\delta}$ & 516 & 586 & 649 & 10.4 & 138.9 \\
$\mathrm{La}_{2} \mathrm{Co}_{0.3} \mathrm{Sn}_{1.7} \mathrm{O}_{7-\delta}$ & 460 & 535 & 597 & 14.9 & 81.0 \\
$\mathrm{La}_{2} \mathrm{Co}_{0.5} \mathrm{Sn}_{1.5} \mathrm{O}_{7-\delta}$ & 462 & 525 & 580 & 15.4 & 101.5 \\
$\mathrm{La}_{2} \mathrm{Co}_{0.7} \mathrm{Sn}_{1.3} \mathrm{O}_{7-\delta}$ & 488 & 541 & 599 & 14.2 & 116.9 \\
$\mathrm{La}_{2} \mathrm{CoSnO}_{7-\delta}$ & 480 & 547 & 614 & 12.6 & 112.3 \\
\hline
\end{tabular}

found that the surface area of Co-doped catalysts varied in good agreement with the reaction activities of methane combustion. For the combustion operated at a high space velocity, a large catalyst surface is required to attain high conversion at a short contact time [2].

In addition, the TPR results are useful to understand the interaction between $\mathrm{Sn}$ and $\mathrm{Co}$ as well as the different activities of $\mathrm{La}_{2} \mathrm{Co}_{x} \mathrm{Sn}_{2-x} \mathrm{O}_{7-\delta}$ catalysts. The better activities of $\mathrm{La}_{2} \mathrm{Co}_{0.3} \mathrm{Sn}_{1.7} \mathrm{O}_{7-\delta}$ and $\mathrm{La}_{2} \mathrm{Co}_{0.5} \mathrm{Sn}_{1.5} \mathrm{O}_{7-\delta}$ can be attributed to the higher oxidation ability reflected by lower reduction temperatures in TPR, the interaction of $\mathrm{Sn}-\mathrm{Co}$ was helpful to reduce the transition metal at high states. Ashcroft et al. have concluded that the high oxidation ability of pyrochores would be resulted from their structure defects [18]. In fact, the structure defects did induce higher oxygen mobility, and the higher redox ability has been confirmed by $\mathrm{H}_{2}$-TPR. Because of the cobalt incorporation into pyrochlore lattice structure defects were produced by the stronger interaction between Sn and transition metals, thus the different redox properties were observed by the TPR and oxidation of methane.

\section{Conclusions}

A series of $\mathrm{La}_{2} \mathrm{Co}_{x} \mathrm{Sn}_{2-x} \mathrm{O}_{7-\delta}$ pyrochlore oxides were successfully synthesized using aqueous precipitation method, characterized by several techniques, and tested for methane combustion. The crystalline phases, specific surface area, redox behaviors and catalytic activities were strongly influenced by the cobalt substitution. Some specific conclusions can be drawn as follows:

(1) The cobalt metal cations are well distributed in the pyrochlore structure and a small quantity of the doped ions in the pyrochlores does not change the crystal purity.

(2) With increases of cobalt content in $\mathrm{La}_{2} \mathrm{Co}_{x} \mathrm{Sn}_{2-x^{-}}$ $\mathrm{O}_{7-\delta}$, the temperature of phase formation of pyrochlore reduces by 50 to $100{ }^{\circ} \mathrm{C}$.

(3) The band maximum, $v(\mathrm{Sn}-\mathrm{O})$, progressively shifts to low frequency, indicating that the $\mathrm{Sn}-\mathrm{O}$ bond strength is weakened with an increase amount of Co doped in the lanthanum stannate pyrochlore.

(4) The Co addition favors the formation of oxygen vacancies. The formation of $\mathrm{La}_{2} \mathrm{Co}_{x} \mathrm{Sn}_{2-x} \mathrm{O}_{7-\delta}$ improves the reduction and reoxidation behavior.

(5) The resultant pyrochlore materials showed enhanced catalytic performance for methane combustion. The best performance was found on $\mathrm{La}_{2} \mathrm{Co}_{0.3} \mathrm{Sn}_{1.7} \mathrm{O}_{7-\delta}$ and $\mathrm{La}_{2} \mathrm{Co}_{0.5} \mathrm{Sn}_{1.5} \mathrm{O}_{7-\delta}$; both catalysts had a lightoff temperature close to $460{ }^{\circ} \mathrm{C}$ with $50,000 \mathrm{~mL} / \mathrm{g} \mathrm{h}$ space velocity and the $\mathrm{La}_{2} \mathrm{Co}_{0.3} \mathrm{Sn}_{1.7} \mathrm{O}_{7-\delta}$ and $\mathrm{La}_{2} \mathrm{Co}_{0.5} \mathrm{Sn}_{1.5} \mathrm{O}_{7-\delta}$ catalyst possessed the optimum ignition activity and complete conversion activity, respectively.

(6) The higher activities of $\mathrm{La}_{2} \mathrm{Co}_{x} \mathrm{Sn}_{2-x} \mathrm{O}_{7-\delta}$ pyrochlore oxides were attributed to (a) higher specific surface areas, (b) the formation of oxygen vacancies by incorporation of Co ions into the pyrochlore lattices, and (c) the improved redox behavior.

\section{Acknowledgements}

This work was financially supported by the National Basic Research Program of China (No. 2004CB719500) and the National High Technology Research and Development Program of China (Project No. 2005AA001020).

\section{References}

[1] H. Arai, H. Fukuzawa, Catalysis Today 26 (1995) 217-221.

[2] K. Eguchi, H. Arai, Catalysis Today 29 (1996) 379-386.

[3] T.V. Choudhary, S. Banerjee, V.R. Choudhary, Applied Catalysis aGeneral 234 (2002) 1-23.

[4] P. Gelin, M. Primet, Applied Catalysis B-Environmental 39 (2002) 1 37.

[5] F. Teng, J.G. Xu, Z.J. Tian, J.W. Wang, Y.P. Xu, Z.S. Xu, G.X. Xiong, F. Teng, Chemical Commununications (2004) 1858-1859.

[6] A.J. Zarur, J.Y. Ying, Nature 403 (2000) 65-67.

[7] M.A. Subramanian, G. Aravamudan, G.V. Subba Rao, Progress in Solid State Chemistry 15 (1983) 55-143.

[8] Y. Teraoka, K. Torigoshi, H. Yamaguchi, T. Ikeda, S. Kagawa, Journal of Molecular Catalysis a-Chemical 155 (2000) 73-80.

[9] J.B. Goodenough, R.N. Castellano, Journal of Solid State Chemistry 44 (1982) 108-112.

[10] Y. Xuan, C.H. He, R. Wang, R. Liu, Y.Q. Jia, Catalysis Letters 46 (1997) 119-121. 
[11] C. Petit, J.L. Rehspringer, A. Kaddouri, S. Libs, P. Poix, A. Kiennemann, Catalysis Today 13 (1992) 409-416.

[12] G.D. Blundred, C.A. Bridges, M.J. Rosseinsky, Angewandte ChemieInternational Edition 43 (2004) 3562-3565.

[13] J.M. Sohn, M.R. Kim, S.I. Woo, Catalysis Today 83 (2003) 289-297.

[14] S. Park, H.J. Hwang, J. Moon, Catalysis Letters 87 (2003) 219-223.

[15] J.M. Sohn, S.I. Woo, Catalysis Letters 79 (2002) 45-48.
[16] M.F.M. Zwinkels, S.G. Jaras, P.G. Menon, Catalysis Reviews Science and Engineering 35 (1993) 319-358.

[17] C. Petit, A. Kaddouri, S. Libs, A. Kiennemann, J.L. Rehspringer, P. Poix, Journal of Catalysis 140 (1993) 328-334.

[18] A.T. Ashcroft, A.K. Cheetham, M.L.H. Green, Journal of Chemical Society. Chemical Communications 21 (1989) 16671669 . 